\section{4 \\ USE OF EQUIVALENT METRIC VALUES IN SCIENTIFIC PAPERS}

$\mathrm{T}$ HE Royal Society Empire Scientific Conference held in June 1946 considered and approved a resolution advocating that where scientific papers or text-books are expressed primarily in British units, provision should be made for the inclusion of metric equivalents or conversion factors.

In July 1947 a letter, signed by the presidents of the Royal Society and of the British Association, the secretary of the Department of Scientific and Industrial Research, the director of the National Physical Laboratory and the chairman of the British Standards Institution Council, was sent to various scientific and technical societies and publishers, directing attention to the resolution and suggesting that, if necessary, a meeting, representative of the various interested organisations, should be held to discuss the implementation of the resolution. Replies to the letter indicated a considerable measure of support for the proposal, and on December 12, 1947, a meeting was held in the rooms of the Royal Society at which methods of implementing the resolution were discussed. This meeting was arranged by the National Physical Laboratory and the director of the Laboratory, Sir Charles Darwin, took the chair.

As an experiment, National Physical Laboratory papers have, since the Conference, so far as possible provided metrical equivalents whenever British units have been used. A paper was therefore prepared at the Laboratory setting out, with examples, ways in which this aim can be achieved; this was circulated to learned societies and institutions and to publishers of scientific text-books and periodicals, to provide a basis of discussion. Thirty-eight societies and thirty-five publishers accepted the invitation and sent representatives to the meeting.

Sir Charles Darwin in opening the meeting emphasized that the matter to be discussed was one of intelligibility only, and had nothing to do with the introduction of the metric system in Britain. By making it possible for the foreigner to convert British units immediately into metric, publishers of scientific papers and books would assist Britain to attain the position of the centre of seience in Europe. A little more work would, of course, be entailed on the part of both authors and publishers, but the addition of a few days to the time normally required for the production and publication of a book was not seriously to be weighed against the great loss of time to all the readers if they had each to look up appropriate factors and make the conversion for themselves. He then referred briefly to the experience gained at the National Physical Laboratory since June 1946 ; this was incorporated in the paper which the meeting had before it for consideration.

Mr. F. A. Gould, a member of the staff of the National Physical Laboratory, in describing the methods of inserting metric equivalents or conversion factors put forward in the paper, said that these incorporated in some way the principle of double entry. For example, where a numerical quantity was cited in the text in English units, the metric equivalent would be given in parenthesis. In some cases such a method would become unwieldy and other devices were suggested. Where the whole text was full of numerical quantities, recourse might be had to a table of conversion factors at the beginning of the paper. Where a numerical table was printed, the
January 24, 1948 vol. 161

conversion factors might be given at its foot, and sometimes to avoid the danger of blunders in the conversion, a single row of the table might also be given in metric form. One of the most effective methods was in diagrams, where it would in most cases be possible to insert additional scales in the metric units.

In the general discussion most speakers expressed a strong dislike of a proposal to give conversion charts in the form of bookmarkers, as these were troublesome to print and were easily mislaid, and suggested as an alternative the use of a 'pull-out'. In order to minimize the additional labour required, there was also a rather natural tendency to favour the method of inserting a list of conversion factors at the beginning of the paper, rather than to give converted figures in the text itself.

The additional paper and extra expense involved in a large amount of double entry, as, for example, in tables, made such a method unpopular with publishers, but it was agreed that in diagrams it would generally be possible to mark ordinates on the left in the British system and on the right in the metric, and that this would make an easy and convenient method of showing the conversion.

The British Medical Association representative outlined the methods which the Association had used without difficulty for some twelve months, and men. tioned how much the inclusion of metric values had been appreciated. A recent document produced by the Association without metric equivalents had brought many protests. Some speakers, in mentioning the need for an authorized list of conversion factors, suggested an extension of the list contained in British Standard Specification No. 350 .

In summarizing, Sir Charles Darwin said that although there were obvious difficulties to be overcome in dealing with the problems concerned with the insertion of suitable metric information in scientific papers, the representatives at the meeting had shown that there was general support for the policy advocated by the Royal Society Empire Scientific Conference, and he felt that by consulting various organisations an acceptable scheme could be produced. Another general meeting did not seem to be required, and the National Physical Laboratory would produce summarized suggestions for distribution to those interested.

\section{SCIENCE MASTERS' ASSOCIATION ANNUAL MEETING}

7 HE forty-fifth annual meeting of the Science Masters' Association was held during December 30-January 2 in the University of Sheffield, under the presidency of the Vice-Chancellor of the University, Dr. J. I. O. Masson, when a full programme of lectures, visits, demonstrations and exhibitions was enjoyed by some four hundred members. The meeting opened with a civic reception in the Town Hall, when the Lord Mayor of Sheffield, Alderman W. E. Yorke, welcomed the Association to the City and, afterwards, with the Lady Mayoress, entertained members to tea.

In his presidential address, Dr. Masson made a strong plea for the recognition of the importance and value of first-hand knowledge. The eminent man of science of real life, unlike his counterpart in fiction, is not the mere possessor of a card-index mind, but derives his store of knowledge from personal 